Meta

Journal des tradlucteurs

Translators' Journal

\title{
Claque ou caoutchouc
}

\section{David Fortin}

Volume 13, numéro 1, mars 1968

URI : https://id.erudit.org/iderudit/002761ar

DOI : https://doi.org/10.7202/002761ar

Aller au sommaire du numéro

Éditeur(s)

Les Presses de l'Université de Montréal

\section{ISSN}

0026-0452 (imprimé)

1492-1421 (numérique)

Découvrir la revue

Citer cet article

Fortin, D. (1968). Claque ou caoutchouc. Meta, 13(1), 25-26.

https://doi.org/10.7202/002761ar d'utilisation que vous pouvez consulter en ligne.

https://apropos.erudit.org/fr/usagers/politique-dutilisation/ 


\section{CLAQUE OU CAOUTCHOUC}

À la consultation sur l'emploi de claque ou caoutchouc qui a paru dans META de septembre $1967^{1}$, nous aimerions ajouter quelques détails. Il faut d'abord noter que la désignation complète de nos claques en anglais est rubber overshoes, parfois abrégée en rubber overs ${ }^{2}$. Le sens que l'on donne au Canada à claque a vieilli, certes. En France, pour désigner cet article de chaussure, on

1. Vol. XII, no 3, septembre 1967, p. 91-92.

2. Cf. le Webster's Third New International Dictionary of the English Language, 1967, et l'édition anglaise du Catalogue Eaton du printemps et de l'été 1967, p. 295. 
utilise de plus en plus surchaussure: tel est le terme technique qui est en voie de simposer. Le Courrier de la normalisation de septembre-octobre $1965^{3}$ renferme une illustration d'une "surchaussure en polychlorure de vinyle 》 (pour badiner, un caoutchouc qui n'est pas fait de caoutchouc naturel). Les Établissements Wattelez ${ }^{4}$, fabricants de chaussures de France, nous signalent que les «surchaussures sont appelées vulgairement caoutchoucs». Le Catalogue Eaton (automnehiver 1967, p. 346) utilise claque, terme qui semble céder peu à peu sa place à caoutchouc dans le Québec.

Quant au deuxième type de rubber overshoes ${ }^{\overline{5}}$, celui qui dépasse la cheville et peut aller jusqu'à mi-jambe, fermé autrefois au moyen d'agrafes et aujourd'hui d'une fermeture à glissière ou d'une courroie, son vrai nom était tout récemment encore galosh, suivant le Webster. Le premier terme que nous ayons entendu en français pour désigner cet article est pardessus. Dans certaines régions, on disait galoches, peut-être sous l'influence de l'anglais. Mais ce mot est toujours français, et le Dictionnaire encyclopédique Quillet (1937) le définit: «Sorte de chaussure dont le dessus est de cuir et la semelle de bois. - Par extension, se dit aussi d'une chaussure de cuir que l'on porte par-dessus les souliers, pour avoir les pieds secs. » Le Catalogue Eaton de Noël 1967 (p. 177) appelle cet article couvre-chaussure, expression qui figure dans le Grand Larousse encyclopédique, au mot caoutchouc, ainsi que dans le Harrap, avant galoche, au mot overshoe.

Mentionnons en terminant que, dans Vie et langage d'août $1967^{\circ}$, le professeur André Rigaud «donne raison au canadien d'avoir refusé l'anglicisme (snow-boots) et conservé le mot ancien (pardessus) que la France a abandonné ».

DAVID FORTIN

3. $\mathrm{N}^{\circ} 185$, p. 670.

4. Poissy (Seine-et-Oise). Communications personnelles des 13 mai et 24 juin 1965.

5. Cf. l'édition anglaise du Catalogue Eaton de Noël, p. 177.

6. № 185, p. 473. 